RESEARCH ARTICLE

\title{
Stories as evidence
}

\author{
Kathleen Murphy-Hollies (D) and Lisa Bortolotti \\ Philosophy Department, University of Birmingham, Edgbaston B15 2TT, UK \\ Corresponding author: Lisa Bortolotti, email: 1.bortolotti@bham.ac.uk
}

(Received 9 September 2021; accepted 14 September 2021)

\begin{abstract}
People often use personal stories to support and defend their views. But can a personal story be evidence? A story tells us that a certain event can happen and has already happened to someone, but it may not always help us understand what caused the event or predict how likely that event is to happen again in the future. Moreover, people confabulate. That is, when they tell stories about their past, they are likely to distort reality in some way. When people who lack access to what motivated past behaviour are asked why they made a choice, they tend to offer plausible considerations in support of that choice, even if those considerations could not have played a motivating role in bringing about their behaviour. When people experience impairments in autobiographical memory, they tend to fill the gaps in their own story by reconstructing significant events to match their interests, values, and conception of themselves. This means that people often offer a curated version of the events they describe. In this paper, we argue that the pervasiveness of confabulation does not rule out that personal stories can be used as evidence but invites us to reflect carefully about what they are evidence of. And this is especially important in the context of digital storytelling, because stories shared on online platforms can exert even greater influence on what people think and do.
\end{abstract}

Keywords: stories; evidence; memory; confabulation; social media; arguments; explanation; justification

\section{Introduction}

Memory is a powerful source of knowledge. When we tell stories about our past, we share significant experiences with others. Sometimes, we use personal stories to support a stance. A man who believes that the threat posed by the coronavirus pandemic has been widely exaggerated may say that COVID-19 is 'just like the flu' because when he tested positive for the virus, his symptoms were a runny nose and a bit of coughing. A general conclusion stems from a specific event.

In some contexts, sharing a story is an important move in a public debate. It may be used to discredit a political opponent or to enhance the credibility of a political ally. During a rally in April 2016, Donald Trump claimed that on 9/11, he helped responders at Ground Zero after the attack to the Twin Towers. With such a story, Trump presented himself as a man of action, generous with his time. However, there are no reports about Trump being at Ground Zero or helping responders on the day of the attack - and indeed

(c) The Author(s), 2021. Published by Cambridge University Press. This is an Open Access article, distributed under the terms of the Creative Commons Attribution licence (http://creativecommons.org/licenses/by/4.0/), which permits unrestricted re-use, distribution and reproduction, provided the original article is properly cited. 
he himself said on a different occasion that he was at home when the planes hit the Towers (Voytko 2020).

Does it matter whether Trump's story is true? We tend to think that it does. If Trump fabricated the story to present himself as a trustworthy leader and a generous person, then the story could backfire, proving that he is happy to lie to enhance his image. But many people genuinely misremember the details of what they did during an unusually emotional or significant event, including 9/11. If Trump did not lie and simply misremembered what happened on that day, then the story would not tell us much about what kind of person Trump is but what kind of person he thinks he is or what kind of person he wants to be. He sees himself as someone who would help the responders after the attack.

The fact that people are vulnerable to memory distortions matters to the project of evaluating stories as evidence. But how? In the section 'Personal stories as evidence', we briefly consider some features of stories that affect their use as evidence. In the section 'Digital storytelling', we reflect on how social media change the way stories are shared and consumed. In the section 'Confabulation', we show how confabulation compromises the reliability of personal stories in clinical and non-clinical contexts. Finally, in the section 'What are stories evidence of?', we point to the positive and negative aspects of the use of personal stories as evidence.

\section{Personal stories as evidence}

In debates that have involved citizens on social media - such as what measures are most effective in tackling the coronavirus pandemic, whether the Earth's climate is changing due to human intervention, or whether electro-convulsive therapy is safe and effective personal stories are often used as evidence for defending some of the debated claims. This invites us to consider some important features of stories.

\section{Relevance}

During the debate about Brexit in the UK, many people campaigning for the UK to leave the EU or justifying their decision to vote leave after the referendum used their own negative experiences with foreign immigrants to support their stance (Stammers and Bortolotti 2020). Experiences of delayed access to healthcare and fewer employment opportunities for British people were interpreted as an effect of excessive and unregulated immigration from the EU. In most cases, though, the stories shared to prove the point did not highlight problems specific to immigration from the EU and did not consider other factors that might have contributed to the problems, such as cuts to healthcare and other austerity measures.

\section{Editing}

Consider the debate about vaccine safety. Many people who oppose immunisations base their arguments on stories of children experiencing ill health, even death, after being vaccinated. Baby Ian Gromowski died after his hepatitis B immunisation. This case is often mentioned as evidence that parents need to consider the risks when agreeing to their children being immunised. The possibilities that other factors might have led to Ian's death are not usually part of how anti-vaccination groups report the story, such as the fact that the baby's mother had a difficult birth, that the baby was allergic to antibiotics, and that he had contracted a virus prior to receiving his immunisation (Shelby and Ernst 2013). Omitting such details may affect how the story is received and enhance its influence as evidence against vaccine safety. 


\section{Causal relationships}

Audiences are not typically alert to the fact that personal stories are used as evidence. We all tend to focus on the relational and aesthetic features of a story rather than its accuracy. In other words, when we attend to a story, we may feel engaged, entertained, or moved if the story is gripping, funny, or touching. However, participants in a public debate need to do more than that: they need to be able to develop a critical attitude towards the story on the basis of whether it succeeds in supporting or challenging the debated claims. Are delays in healthcare provision due to the UK being in the EU? Was baby Gromowski's death caused by his hepatitis B immunisation? Unless answers to questions about causal relations between events can be answered, the story may fail to provide conclusive or even convincing evidence for the claim it allegedly supports.

\section{Motivation}

When we attend to personal stories, we are likely to be motivated by them, more so than by other forms of evidence. This gives rise to the identifiable victim effect (Jenni and Loewenstein 1997). In the context of charitable donations, people are more likely to act on the basis of the vivid recount of an individual's adverse experience than by statistical information informing them about a threat for a far greater number of people. This is because people prefer to act to stop a threat that is certain as opposed to a threat that is just probable, and they are sensitive to the percentage of individuals they can save, given the appropriate reference class. Donors reading the case of a young African girl dying of malnutrition believe that by donating to the cause they will definitely save that girl. Statistical information about a third of African children dying of malnutrition is not equally motivating because potential donors feel that the outcome is less certain.

\section{Windows into another world}

Sharing a personal story is mostly apt to capture a person's perspective on an event or an experience that may not be shared by others - the story may be the only source of information about what storytellers are going through when their situation is different from their audience's. Take first-person accounts of ill-heath or disability: such stories make it possible for everyone to understand the challenges caused by a debilitating condition and better inform support services (Bortolotti and Jefferson 2019). Another example is when people belonging to an ethnic minority report instances of racism in the place where they work: their stories are good evidence for the claim that there is a problem with racism that needs to be addressed in that workplace, a problem that others may not have been able to identify on their own.

\section{Reliability}

Whether the story is an accurate representation of reality depends on the storyteller's perceptual, introspective, and inferential capacities, and also on their standpoint and character. Did they directly experience the information they are sharing? Did they have special access to that information? Are they being intellectually honest? All of these questions are important, but it is difficult to address them in general terms. In the rest of this paper, we shall focus on a reliability question that applies to all cases in which people tell personal stories: is the storyteller vulnerable to confabulation? People confabulate when, without any intention to deceive, they describe or explain an event when they have no access to the evidence that would support the accurate description or explanation of that event (Bortolotti 2018). Confabulation is part and parcel of how people reconstruct their past and we will return to it in the section 'Confabulation'. 


\section{Digital storytelling}

One important issue in considering stories as evidence is how the medium used to share the story affects its content, structure, and reach. Storytellers can make use of different tools seamlessly in digital storytelling, using text updates, hashtags, photos, links, GIFs, videos, sounds, and emoticons to share their experiences but also to participate in a debate or campaign for a cause. How do personal stories shared online differ from stories shared in the pub or at work?

\section{Digital stories are co-constructed}

Online stories are typically co-constructed. In something like a Facebook status update, people co-construct storyworlds because multiple storytellers are engaged via the practices of commenting, liking, linking, tagging, and sharing photos (Page et al 2013). This enables people who may be geographically or culturally apart to develop a shared story that contributes to their identities. The sharing of personal stories is identified as the main purpose of Twitter, but story ownership is complicated on social media, as the telling of a personal experience often involves multiple storytellers and the plotline is subject to changes during the telling and sharing of the story (Dayter 2015). While these social media practices undoubtedly bring people together, and encourage social interaction and group identity, determining authorship and authenticity may be more of a challenge for digital storytelling. A story can be told first by one user for one purpose and then hijacked for a different purpose by other users in a way that is not always transparent to the wider audience.

\section{Digital stories are identity building}

The same type of content, say images, can also be made to play different roles and tell distinct aspects of a story. The successful use of Instagram by a presidential candidate was analysed in the 2016 Austrian election campaign (Liebhart and Bernhardt 2017). The content posted on the platform had different purposes: document the campaign; demonstrate people's support for the candidate and the candidate's approachability; report the candidate's media work; call people to action, e.g. to make donations; provide a background story for the candidate, revealing him to be authentic as a person with certain interests and values; clarify the candidate's position on a number of important issues.

In a study of people posting images on Instagram and Snapchat during a visit to a museum (Villaespesa and Wowkowych 2020), there is also a wide range in visitors' main motivations for sharing; communicating the emotions they felt when seeing the artwork; getting other people to appreciate art and visit the museum; expressing their identity - which includes supporting something that is important to the person they feel they are. For instance, one visitor said:

Then this was Rosa Parks, you know the bus situation, sitting in coloreds only, sitting in the back of the bus and things like that. And this particular photo I like, of course because I am African American and my father actually marched with Dr. Martin Luther King.

\section{Digital stories have a wider reach}

One observation made both by researchers interested in the political uses of social media and by those studying the effects of sharing aesthetic experiences is that digital storytelling sparks interactions faster and on a bigger scale. As we saw, the story can have different aims, is actively enriched by participants on the relevant social media platform, and 
can be interpreted and shared further in ways that are not consistent with the original storyteller's intentions. Such features are not unique to digital storytelling. However, as misinformation experts have emphasised (e.g., O'Connor and Weatherall 2019), the influence of digital storytelling is far-reaching and more amplified than the influence of traditional storytelling, because the story is available, immediately, to a much bigger audience.

This explains the quick spreading of conspiracy theories in the age of social media: although there has always been a tendency for people towards conspiratorial ideation, especially during times of crisis, the impact of conspiracy theories shared globally via digital storytelling is greater. Thus, when the story is supposed to serve as evidence, it is important to examine the reliability of the source.

\section{Confabulation}

In the section 'Personal stories as evidence', we talked about how personal stories can fail at supporting a general claim. One of the reasons for concern was the tendency people have to confabulate, that is, to reconstruct their past in a way that others find inaccurate or badly supported by evidence. Here, we would like to say more about confabulation, starting with two examples:

Interview: An employer is hiring for a new position and is looking through the CVs of the applicants. She chooses to invite George for an interview instead of Rabia. When the employer is asked by the panel why she chose George instead of Rabia, she says that George's CV was better than Rabia's. However, the candidates' CVs were of comparable strength. The employer does not have introspective access to any implicit biases that may have influenced her choice to interview George rather than Rabia and gives an answer by which she seemingly justifies her decision and her belief that George is a better choice.

Care Home: A patient with dementia is in a care home. She explains her unfamiliar surroundings by saying: 'I am at work'. When she is asked by another resident to explain the presence of nurses and family members, she elaborates: 'Well, we are having renovations and building work done, these people are helping'. She does not have access to the relevant information that the building is a care home, that she has dementia, and that those people are there to keep her safe, but she has an explanation of the events that works for her and she sincerely endorses.

A common case of confabulation is when a person offers an explanation for why they acted in a certain way without being aware of the factors responsible for that action. Often, confabulations distort reality or misrepresent the specifics of the person's circumstances. Crucially, confabulators are not aware of the falsity or ill-groundedness of their explanations and therefore cannot be said to have any intention to deceive. They tend to be confident in their confabulations and are often, but not always, resistant to updating their explanations in the face of counter-evidence (Bortolotti and Cox 2009, 956).

In Interview, the employer displays non-clinical, everyday confabulation. Her confabulation is provoked because, without having been questioned, she may not have considered why she chose George over Rabia. Provoked confabulations tend to be momentary, whereas spontaneous confabulations are more likely to be persistent, as there may be a consistent 'outpouring' of false memories (Bortolotti and Cox 2009, 953). The latter is more commonly associated with confabulation seen in the context of psychiatric illness.

In Care Home, the patient shows spontaneous clinical confabulation because she offers the initial explanation of the unfamiliar surroundings unprompted and continues to 
explain subsequent events with further confabulations. The confabulation may be a core symptom of the illness or a way to explain sensations and beliefs occurring to the patient because of their condition. Confabulation is commonly associated with Korsakoff's syndrome, amnesia, and anosognosia (Hirstein 2005, 8). In Care Home primary and secondary confabulations are both exhibited; in a manner akin to storytelling, the patient's initial confabulation that she is at work is developed with further claims about the presence of family and nurses, which would be explained by renovation works being carried out.

Neither of the confabulatory explanations is based on the features of the situation for which the explanation is offered. In Interview, the CVs of the job candidates were of comparable strength, and so the claim that George's CV was better than Rabia's cannot explain how the employer came to her decision. In Care Home, the unfamiliar surroundings do not belong to a workplace, and renovations are not in progress, and so these statements do not account for why the patient finds herself in a home surrounded by nurses and family members.

It is a curious but defining feature of confabulation that the person does not realise that they do not know what caused their experience or what has driven their behaviour. In Interview, the employer lacks access to the accurate explanation of her choice, because she does not have an insight into her implicit bias in favour of George. In Care Home, due to dementia, the patient lacks access to the autobiographical events that would support an accurate explanation of her situation - she does not realise that she needs to be cared for in a care home.

Why are people so keen to 'fill in' gaps in their understanding of reality and of themselves, despite not having access to the relevant evidence? A number of possible reasons are discussed in the literature. People may be motivated to preserve a sense of agency, a sense that they can influence what happens around them and act in such a way as to fulfil their goals. They have a desire not to be dumbfounded and humiliated by not being able to articulate the reasons for their own behaviour (Sullivan-Bissett 2015, 552). Moreover, people may fill the gaps in the way they do because they are also motivated by the desire to preserve positive self-representations. The employer in Interview wants to be a fair and competent decision maker who is neither sexist nor racist. The dementia patient in Care Home sees herself as a self-sufficient, independent person as opposed to a person facing debilitating illness and needing care (Bortolotti and Sullivan-Bissett 2018).

In some situations, the consumption of digital stories that resonate with one's values makes it more likely that there are confabulations readily available to use when an explanation is needed. Consider a third example, the case of some college students who are invited to explain why they do not wear face masks during the pandemic.

Mask Mandate: A student is prevented to access college buildings because their institution has implemented a state-wide mask mandate. Together with some friends, the student starts a protest and is asked by the local press: 'Why are you protesting? Why don't you want to wear a mask?'. Students respond by availing themselves of explanations and justifications that have been offered on social media by political leaders and campaigners in the previous weeks. When making sense of their own choices, they express their views along these lines: 'It is our faces, we decide what to do with them', 'Ours is a fight for freedom', 'We do not belong to the government or to the college'. They tell a story where the refusal to wear a mask is a point of principle, namely a defence of their individual freedom. The factors leading to their behaviour may be different, though, and include considerations about convenience, a desire for non-conformity, denial of the health threat, scepticism about the effectiveness of masks, or a desire for normality, just to mention a few. (For the real-life case inspiring this example, see Smith 2021.) 
In general, people have a strong need to gain a causal understanding of their behaviour and their circumstances (Coltheart 2017) and stories are what they use to make sense of themselves and the world around them (Bruner 2003). In Interview, the employer needs to justify her decision to the panel. In Care Home, the dementia patient needs to know where she is so that she can interact with the surrounding environment. In Mask Mandate, students need to explain why they are not following the rules. People's desired causal understanding often takes a narrative form and becomes an engaging story: we are all motivated to give our lives the shape of an easy-to-understand, ongoing narrative (Örulv and Hydén 2006), possibly with an upward trajectory (McAdams 2001) that indicates we are being true to ourselves and making progress.

Although stories often reflect people's biases and the limited information available to them, stories also enable people to connect with others by sharing meanings and themes from their lives (Stammers 2020) and to justify their behaviour to themselves and others, signalling that they are rational and trustworthy after all (Ganapini 2020).

\section{What are stories evidence of?}

As we saw, even the photo of a political candidate's childhood vacation in the mountains when posted by his campaign team - and the photo of an artwork snapped during a museum visit - when the artwork depicts a civil-rights activist - can be stories used as evidence. The vacation shot is turned into evidence that the candidate is an authentic, wellrounded person who loves his homeland and is connected to his roots. The picture of the artwork becomes a reminder that the fight for equality needs to continue, inspired by the actions of the leaders and role models of the past.

There are many illustrations of the powerful role of stories as evidence in debates. The case of a teen in the United States who sought vaccination against his mother's will raised concerns about the reliance of anti-vaxxers on storytelling (Helmore 2019).

Lindenberger said he had learned that his mother's unproven fears against vaccinations was received 'anecdotally', including a mistaken belief that the measles-mumps-rubella (MMR) vaccine raises the risk of autism in children, despite extensive scientific research that shows it does not.

'There's an important decision to be made between information provided,' Lindenberger said. 'Many people don't resonate well with data and numbers they resonate better through stories.'

We see that with the anti-vaccine community. A lot of the foundation they build with parents is on an anecdotal level, sharing stories and experiences. That speaks volumes to people because it reaffirms, especially for my mom, that her position is correct.

In the recent debate about the safety of COVID-19 vaccines, stories have been used to persuade participants of the debate of the risks of vaccination (by vaccine sceptics) but also of its benefits (by health authorities). Such stories, often including highly emotional content, seem to be taken in much higher regard and to have more significant effects on behaviour than other forms of evidence, such as diagrams comparing the risks of vaccination with the risks of catching COVID-19. This shows that stories are not just a problem for effective science communication - because they attract more attention than other data but may also inspire a solution. By grabbing attention with a story, science communicators can encourage health-promoting behaviours.

It is now more readily recognised in the literature that stories often aim to persuade in the context of debating controversial issues and are generally successful at doing 
so precisely because they do not have a traditional argumentative structure (Kubin et al 2021):

The rich literature on political persuasion further highlights the ability for narratives to persuade - often because narratives typically present information 'peripherally,' minimizing the likelihood for counterarguments from 'central' processing.

For the authors, divulging personal experience of harm is the most effective way to persuade opponents to bridge disagreements and political divides, and gains storytellers respect to a greater extent than citing facts or articulating arguments.

In a recent discussion of governmental pro-vaccination campaigns at the time of COVID-19, stories are also considered more effective than other forms of information (Rogers 2021):

Evidence suggests vaccine-hesitant groups are less likely to respond to factual information particularly from 'pro-vaccine' sources. But they may respond more to personal stories about the effects of the virus. In my area of research, we call these stories 'cultural health narratives'. Within the anti-vax movement, these narratives are often powerful stories of people negatively affected by vaccinations, or what they believe are vaccine-related side effects. These emotional accounts are very powerful because we're attracted to narratives and we live our lives through them.

Stories are also described as the way forward when attempting to persuade people to accept health interventions that are potentially risky (Rogers 2021):

When we hear a story, we often lower our guard and tend to start responding emotionally to the characters. Parents, educators and religious leaders have long used this as a way of teaching. Governments could use storytelling to potentially improve COVID vaccination rates particularly among those who are unlikely to get the jab. Governments could add emotional health stories to their vaccination messages. These narratives could show the negative effects of the virus on people's lives, and/or they can be used to show the positive effects of vaccinations to help avoid disease.

In the climate change wars, the role of stories, when vividly presented by journalists, has been also acknowledged as a game changer. In a recent interview (Buonocore 2019), the author Dan Fagin says:

[T] he journalists that are having the greatest impact on their work on climate change have chosen to tell true stories of people impacted, presenting them with empathy. Their work is building an understanding in the broader public that, whether you believe in climate change or not, the weather is changing, it is affecting people's lives, and we need to help these people. If journalists are able to work this way, they are more likely to make a difference and bring positive change. In my experience, the best climate writers are aware of this.

We know that people do not retain dry information and data. It doesn't resonate with people emotionally. If we want people to remember something, and ultimately act on it, the content needs to come in the form of a story, in the form of narrative, with characters, drama and a connecting thread. Journalism needs all these things in order to be impactful and make a difference in people's lives. 
If stories can both distract from and enhance science communication, what seems to be essential is to support the capacity for citizens to discriminate between 'good' and 'bad' stories, or stories that constitute good evidence from stories that do not. Although all stories are interesting and informative as 'windows into another world', only some stories are convincing evidence for a controversial position in a debate. The fact that stories are used in debates requires us to establish some criteria of evaluation for stories as evidence that can be easily applied.

That is too ambitious a goal for our present purposes, but here is a first step in what seems to us the right direction. In the context of a debate, we need to know what stories give us information about. In first-person accounts of people who describe what they are or what they did, the widespread phenomenon of confabulation suggests that the accounts may reflect how people see themselves, and how they want to be seen by others, and not how they actually are. In Interview, the employer wanted to present herself as a rational decision maker; in Care Home, the dementia patient wanted to project an image of independence and self-sufficiency; and in Mask Mandate, the students wanted to be seen as defenders of individual freedom against the overreach of powerful institutions.

More generally, first-person accounts of people who explain their behaviour are projections of what people see as the representative reasons behind their actions and choices, as opposed to an accurate causal account of the relevant factors leading to their behaviour. For instance, in Interview, the employer wants to present the choice of George as the outcome of a decision-making process based on the relevant evidence, as opposed to the outcome of a racist or sexist bias. In situations that are novel and puzzling, the story may be an attempt to provide a causal account of the events that is meaningful to the person given their previous experience or future goals. In Care Home, the dementia patient uses the general knowledge available to her to make sense of the features of her environment, rendered confusing by her memory impairment. And in Mask Mandate, it is the consumption of certain rhetoric on social media, a constant association between the refusal to comply with safety regulations and the love of freedom, that influences the students' understanding of their own choices.

The tendency to confabulate and the prevalence of the phenomenon do not render all stories 'bad' evidence by default. Rather, they show that we need to acknowledge the importance and value of people's sense of themselves as capable of intervening in their environment, as agents, in remembering, reporting, and constructing their own experiences. Pointing to the potential risks of confabulation does not mean that storytellers should be blamed for the fact that their stories are unreliable or ill-grounded. When people seek a causal understanding of their problems ('I cannot get an appointment with my doctor') or tragic events in their lives ('Baby Gromowski died'), they respond to significant setbacks and even tragedies by attempting to restore a sense of order and control that is central to their agency. They want the problem to be solved and the tragic event to never occur again. There is nothing blameworthy in seeking a causal explanation for those purposes - and the explanation is only as good as the information people can access and process. So, the difficulty in accessing healthcare is attributed to excessive immigration and the death of the baby is attributed to his recent immunisation. In this way, people place a short-term defeat in a bigger framework that enables them to cultivate some hope for the future: 'After Brexit, EU citizens won't be able to access healthcare services and my doctor will have more time for me'; 'Baby Gromowski is dead, but I will do all I can to prevent other babies from dying'.

Even when people confabulate, their stories can provide valuable information. Confabulations may not be the descriptions and explanations of the events supported by the best evidence, but they tell us something. By listening to people's stories, we learn about their values and appreciate what they care about and what motivates them. 
This helps us see the world through their eyes, bringing to the fore issues that we might have dismissed otherwise, often from a position of ignorance or privilege. Just like the use of stories can be deployed in science communication or scaremongering - e.g., to educate people about vaccines or to persuade them that vaccines are unsafe - confabulatory explanations can have some use depending on how they are constructed, shared, and received. We can learn from stories involving confabulation. When used as an argument against vaccine safety, an account of how an immunisation in childhood resulted in a person's health problems may not teach us about the actual effects of vaccines or why pharmaceutical companies develop them. But it can teach us about that person's fears and values, and how they make sense of their own experiences. This can inform further interactions with the person who told the story and future attempts at communicating science to people who are likely to share the same fears and values.

How are debates taking place in a digital landscape affected by confabulation? As we saw, confabulation is partly driven by the motivation to order individual experiences into meaningful narratives and to build and reflect on identities that users share with others. Platforms on social media offer multiple ways to achieve those goals, providing a vast audience for people's stories - this is probably why people are so drawn to using those platforms. Because of the increased reach of digital storytelling, users consume many shared stories, stories that inspire them and resonate with them. What audiences may not realise is that some of those stories are used as evidence for controversial claims, and resources are needed to evaluate the causal connections that would make those stories good evidence for said claims. When such resources are unavailable, misinformation involving inaccurate causal explanations can be disseminated widely and quickly.

\section{Conclusions}

In personal stories, people make sense of significant events in their lives and project their image of themselves. Experiences are often remembered in such a way as to fit into the wider scheme of the person's goals and sense of purpose. These influences can become more powerful in people whose executive processes are compromised, because memory retrieval in clinical confabulation is more heavily driven by motivational factors and less effectively checked against other memories (Fotopoulou 2009, 278-280).

With personal stories, people do not merely share experiences but also argue for a particular, often controversial, viewpoint. Stories are informative whether or not they involve confabulation. Not only do they point to what the storyteller cares about, but they also tell us about what the storyteller values and what kind of person they aspire to be. But stories are not by themselves evidence for the viewpoints they are used to support. Brexit may not be the solution to the problems of national healthcare provision. Refusing immunisations may not prevent babies from dying. Independent evidence is needed for causal claims to be established.

In other words, stories as evidence for controversial claims need to be critically assessed, especially when they are shared on online platforms and have a greater reach and influence on public opinion. This might enable us to prevent misinformation and enhance the quality of debate among citizens. Acknowledging at the same time people's irresistible attraction to stories and their vulnerability to confabulation is instrumental to developing a satisfactory evaluative framework.

Acknowledgements. In the preparation of this article, the authors acknowledge the support and feedback of the Women in Philosophy group and the Belief and Delusion reading group at the University of Birmingham. 
Data availability statement. The current research article analyses and interprets data that have been previously published. References to the original articles have been provided throughout.

Funding. This work received no specific grant from any funding agency, commercial, or not-for-profit sectors.

Competing interests. L.B. and K.M.-H. declare none.

\section{References}

Bortolotti L (2018) Stranger than fiction: Costs and benefits of everyday confabulation. Review of Philosophy and Psychology 9(2), 227-249.

Bortolotti L and Cox R (2009) 'Faultless ignorance': Strengths and limitations of epistemic definitions of confabulation. Consciousness \& Cognition 18(4), 952-965.

Bortolotti L and Jefferson A (2019) The power of stories: Responsibility for the use of autobiographical stories in mental health debates. Diametros 60, 18-33.

Bortolotti L and Sullivan-Bissett E (2018) Epistemic innocence of clinical memory distortions. Mind \& Language 33(3), 263-279.

Bruner J (2003) Making Stories. Cambridge, MA: Harvard University Press.

Buonocore M (2019) Storytelling is part of the solution to the climate dilemma-interview with Da Fagin. Foresight, 3 April. Available at https://www.climateforesight.eu/future-earth/storytelling-is-part-of-thesolution-to-the-climate-dilemma/ (accessed 1 July 2021).

Coltheart M (2017) Confabulation and conversation. Cortex 87, 62-68.

Dayter D (2015) Small stories and extended narratives on Twitter. Discourse, Context \& Media 10, 19-26. doi:10.1016/j.dcm.2015.05.003.

Fotopoulou A (2009) Disentangling the motivational theories of confabulation. In Hirstein W (ed.), Confabulation: Views from Neuroscience, Psychiatry, Psychology and Philosophy. New York: Oxford University Press, pp. 263-289.

Ganapini MB (2020) Confabulating reasons. Topoi 39(1), 189-201.

Helmore E (2019) I defied mother to get vaccinated for safety of me and others, US teen says. The Guardian, 5 March. Available at https://www.theguardian.com/us-news/2019/mar/05/ethan-lindenberger-ohio-congressvaccines (accessed 1 July 2021).

Hirstein W (2005) Brain Fiction: Self-deception and the Riddle of Confabulation. Cambridge: MIT Press.

Jenni K and Loewenstein G (1997) Explaining the identifiable victim effect. Journal of Risk and Uncertainty 14(3), 235-257. doi:10.1023/A:1007740225484.

Kubin E, Puryear C, Schein C and Gray K (2021) Personal experiences bridge moral and political divides better than facts. Proceedings of the National Academy of Sciences 118(6), e2008389118. doi:10.1073/pnas.2008389118.

Liebhart K and Bernhardt P (2017) Political storytelling on Instagram: Key aspects of Alexander Van der Bellen's successful 2016 presidential election campaign. Media and Communication 5(4), 15-25. doi:10.17645/ mac.v5i4.1062.

McAdams DP (2001) The psychology of life stories. Review of General Psychology 5(2), 100-122.

O'Connor C and Weatherall Jo (2019) The Misinformation Age. New Haven, CT: Yale University Press.

Örulv L and Hydén LC (2006) Confabulation: Sense-making, self-making and world-making in dementia. Discourse Studies 8(5), 647-673.

Page R, Harper R and Frobenius M (2013) From small stories to networked narrative: The evolution of personal narratives in Facebook status updates. Narrative Inquiry 23(1), 192-213.

Rogers M (2021) Why telling stories could be a more powerful way of convincing some people to take a COVID vaccine than just the facts. The Conversation, 15 February, 254-267. Available at https://theconversation.com/ why-telling-stories-could-be-a-more-powerful-way-of-convincing-some-people-to-take-a-covid-vaccinethan-just-the-facts-155050 (accessed 1 July 2021).

Shelby A and Ernst K (2013) Story and science: How providers and parents can utilize storytelling to combat anti-vaccine misinformation. Human Vaccines \& Immunotherapeutics 9(8), 1795-1801. doi:10.4161/hv.24828.

Smith B (2021) Students protest state's school mask mandate. CBSN Pittsburgh, 7 September. https://pittsburgh. cbslocal.com/2021/09/07/greater-latrobe-high-school-face-mask-protest/ (accessed 1 July 2021).

Stammers S (2020) Confabulation, explanation, and the pursuit of resonant meaning. Topoi 39(1), 177-187.

Stammers S and Bortolotti L (2020) When the personal becomes political: How do we fulfil our epistemic duties relative to the use of autobiographical stories in public debates?. In McCain K and Stapleford S (eds), Epistemic Duties: New Arguments, New Angles. New York: Routledge, pp. 254-267.

Sullivan-Bissett E (2015) Implicit bias, confabulation, and epistemic innocence. Consciousness and Cognition: An International Journal 33, 548-560. https://doi.org/10.1016/j.concog.2014.10.006 
Villaespesa E and Wowkowych S (2020) Ephemeral storytelling with social media: Snapchat and Instagram stories at the Brooklyn Museum. Social Media + Society 6(1), 1-13. doi:10.1177/2056305119898776.

Voytko L (2020) A timeline of Trump's misleading 9/11 claims. Forbes, 11 September. Available at https://www. forbes.com/sites/lisettevoytko/2020/09/11/a-timeline-of-trumps-misleading-911-claims/?sh=212d2d085836 (accessed 1 July 2021).

Kathleen Murphy-Hollies is a doctoral researcher at the University of Birmingham (UK), specialising in the area at the intersection of ethics and the philosophy of the cognitive sciences. Her doctoral project is about the impact of confabulation on how agents embody moral virtues.

Lisa Bortolotti is Professor of Philosophy at the University of Birmingham (UK) specialising in the philosophy of the cognitive sciences, philosophy of medicine, and issues in biomedical ethics. Her main interest is in the strengths and limitations of human agency and she has written extensively on delusion and confabulation.

Cite this article: Murphy-Hollies K, Bortolotti L (2022). Stories as evidence. Memory, Mind \& Media 1, e3, 1-12. https://doi.org/10.1017/mem.2021.5 